\title{
QUANTITATIVE SIGNIFICANCE OF TRACE ELEMENTS IRON (Fe), MANGANESE (Mn) AND MOLYBDENUM (Mo) ON GROWTH AND SPORULATION OF PYRICULARIA ORYZAE
}

SANDEEP SHUKLA \& RENUBALA SHARMA

Department of Botany, Govt. E.V.P.G. College, Korba C.G. - India

\begin{abstract}
Pyricularia oryzae is one of the most primary causes to destroy Rice crop in all the Rice producing countries. It causes Blast disease in Rice, other species of Pyricularia also infect the different monocot plant. Humidity, temperature, Rainfall and nutrients are the major factors which control the growth and spread of the Pyricularia oryzae.

Some nutrients in very small quantities are required for the growth, development, and other physiological and metabolic activities of the fungi. In P. oryzae we can control the production of spores and growth by changing the quantity of these trace elements.

In the present study, we tried to understand the effect of three trace elements or micronutrients i.e. Iron (Fe), Manganese (Mn), and Molybdenum (Mo) on spore formation and growth efficiency of P. oryzae.5 ppm (part per million) concentration of $\mathrm{Fe}$ is most suitable for optimum spore formation and growth in Pyriculariaoryzae when we increased the concentration of $\mathrm{Fe}$ in the media is poses a negative effect. Mn is required in a little more quantity than Fe. As we increased Mn concentration growth and sporulation increased respectively. On other hand, controlled quantity of Mo is sufficient for growth and sporulation. The increase in a small quantity of Mo in the medium poses a negative effect on Pyricularia oryzae growth and spore production. So, by manipulating quantities of these trace elements in the food chain, we can control blast disease.
\end{abstract}

KEYWORDS: Trace element, Pyricularia, Blast disease, Micronutrients

Received: Nov 01, 2020; Accepted: Nov 30, 2020; Published: Dec 17, 2020; Paper Id.: IJBRDEC20209

\section{INTRODUCTION}

Pyricularia oryzae is a specific pathogen for Blast disease of the rice. The sexual stage of the fungi is also known as Magnaporthe oryzae. Blast is a very common and widely distributed Rice disease, and cause of up to $30 \%$ yield loss worldwide (Skamnioti et al .2009).Pyricularia oryzae is a host-specific fungus, many other species of Pyricularia infect other monocots.

Rice is the main food item for more than half the population of the world. Most Asian countries including India are the major producer of Rice. A decrease in the production of Rice poses a real threat to starvation.

The blast disease of rice caused by $P$. oryzae affects all aerial parts of the Rice plant. Most of the symptoms are visible on the leaves, a gray or white lesion on the panicles, which turn white and die before the grains are filled (S.C. Scardaci et al. 1997) ${ }^{[1]}$. For the Rice plant Pyriculariaoryzae is highly specific. The blast disease was recorded more than three centuries ago in Asia and is now reported from more than eighty countries. 
About 17 elements are required to meet the nutritional requirements of the fungi (Godbold and Hittermann 1985, Breckle 1991, Nies 1999) ${ }^{[2-4]}$. Some element which is present is very minute quantity is called trace element. The previous studies conducted by Sharma and Shukla $(2020)^{[5]}$,Foster(1939) ${ }^{[6]}$, Allaway (1965) ${ }^{[7]}$, Lily (1965) ${ }^{[8]}$, Bowen (1966) ${ }^{[9]}$. Trace elements $\mathrm{Zn}, \mathrm{B}, \mathrm{Mg}, \mathrm{Fe}, \mathrm{Mn}, \mathrm{Cu}, \mathrm{Mo}$, and $\mathrm{Ca}$ are essential for the proper development of almost all the fungus, revealed by Thind and Mira Madan (1977). ${ }^{[10]}$

The current study reveals the role of Fe, Mn, and Mo on the growth and spore development of Pyriculariaoryzae.

\section{MATERIALS AND METHOD}

Until washing in distilled water, the glassware was soaked in chromic acid for a few hours. For 2 hours the glassware was sterilized at $120^{\circ} \mathrm{C}$. As micronutrients, the following chemicals were used (Table 1).

Table 1: Micronutrients and Chemical Salt

\begin{tabular}{|l|l|l|}
\hline \multicolumn{1}{|c|}{ Micronutrients } & \multicolumn{1}{|c|}{ Salt } & \multicolumn{1}{c|}{ Chemical formula } \\
\hline Iron $(\mathrm{Fe})$ & Ferrous Sulphate & $\mathrm{FeSO}_{4} .7 \mathrm{H}_{2} \mathrm{O}$ \\
\hline Manganese $(\mathrm{Mn})$ & Manganese Chloride & $\mathrm{MnCl}_{2} .4 \mathrm{H}_{2} \mathrm{O}$ \\
\hline Molybdenum $(\mathrm{Mo})$ & Sodium Molybdenum & $\mathrm{Na}_{2} \mathrm{MoO} . \mathrm{H}_{2} \mathrm{O}$ \\
\hline
\end{tabular}

The amount of the test compound nutrients (Fe, Mn, Mo) were dissolved in 1000ml. of double distilled water for preparation of stock solution. The quantity was determined by dividing the compound's molecular weight by the trace elements molecular weight. . For each compound the stock solution was prepared (table 2). This stock solution formulated was concentrated at $1000 \mathrm{ppm}$.

Table 2: Stock Solution of Trace Elements at a Concentration of 1000.

\begin{tabular}{|c|c|}
\hline Trace Elements & $\begin{array}{c}\text { Amount Dissolved in 1000 ml. } \\
\text { Distilled Water (mg) }\end{array}$ \\
\hline $\mathrm{FeSO}_{4} .7 \mathrm{H}_{2} \mathrm{O}$ & 497 \\
\hline $\mathrm{MnCl}_{2} .4 \mathrm{H}_{2} \mathrm{O}$ & 360 \\
\hline $\mathrm{Na}_{2} \mathrm{MoO} . \mathrm{H}_{2} \mathrm{O}$ & 252 \\
\hline
\end{tabular}

The amount of different trace elements was determined according to the standard formula given below-

$\mathrm{C} 1 \times \mathrm{V} 1=\mathrm{C} 2 \times \mathrm{V} 2$

Where, $\mathrm{C} 1=$ Required concentration of test trace elements.

$\mathrm{V} 1$ = Required volume of medium.

$\mathrm{C} 2=$ Concentration of the trace elements stock solution $(1000 \mathrm{ppm})$.

$\mathrm{V} 2=$ Required volume of test trace elements.

$\mathrm{Ph}$ of the media was maintained to 7.0. Pre sterilized Cz-Fe medium containing various concentrations of the test micronutrients is poured into sterile petri-plates and each plate was incubated with $5 \mathrm{~mm}$ diam. after solidifying. For each concentration of trace element, five replications were made. The plates were incubated up to 96 hours at $27 \pm 1^{\circ} \mathrm{C}$.

Rice plants infected with blast disease were collected from surrounding areas of Korba, Chhattisgarh. Small pieces from the infected stem were taken and sterilized with $0.5 \%$ Sodium hypochlorite for 1 minute and then washed. 
Pieces of infected stem are aseptically transferred into petri plates containing PDA medium. At $27 \pm 1^{\circ} \mathrm{C}$ for 96 hours, the plates were incubated. The pure culture was further transferred to $\mathrm{Cz}-\mathrm{Fe}$ and incubated after the growth of the fungi. One week old culture was cut into $5 \mathrm{~mm}$ diameter disc and used for different experiments.

Same time, spore formation was also reported (few, good, very good in numbers).Five replication were made for each treatment and proper control i.e. without test trace element was maintained in each case.

\section{RESULT AND DISCUSSION}

(A)

Effect of Iron (Ferrous sulphate) on growth and microsclerotia formation of Pyricularia oryzae

Table 3

\begin{tabular}{|c|c|c|c|c|}
\hline \multirow{2}{*}{$\begin{array}{c}\text { Concentration } \\
(\mathbf{p p m})\end{array}$} & \multicolumn{3}{|c|}{ Radial Growth $(\mathbf{m m}) *$} & \multirow{2}{*}{$\begin{array}{c}\text { Microsclerotia } \\
\text { Incubation Time (hour) }\end{array}$} \\
\cline { 2 - 4 } $\begin{array}{c}\text { Formation at 96 hrs of } \\
\text { Incubation }\end{array}$ \\
\hline 0 & $\mathbf{2 4}$ & $\mathbf{4 8}$ & $\mathbf{7 2}$ & + \\
\hline 2 & 25.6 & 73.2 & 80.5 & ++ \\
\hline 5 & 27.0 & 74.0 & 82.6 & ++ \\
\hline 10 & 28.4 & 75.2 & 83.5 & ++ \\
\hline 20 & 20.8 & 68.4 & 78.4 & + \\
\hline
\end{tabular}

*Average of 5 replication; one plate constitute one replication

+ Less than 5 sclerotia/objective

++ 6-10 sclerotia/objective

+++ More than 10 sclerotia/objective

Between macro and micro essential elements Fe seams to hold an intermediate position. When we supplied different concentrations of $\mathrm{Fe}$ into the media, radial growth is slightly increased up to $2 \mathrm{ppm}$. Maximum radial growth is observed in $5 \mathrm{ppm}$ where radial growth is $28.4 \mathrm{~mm}$ in 24 hours, $75.2 \mathrm{~mm}$ in 48 hours, and $83.5 \mathrm{~mm}$ in 72 hours. After that radial growth is decreased as we increased concentration e.g.10 and $20 \mathrm{ppm}$ (table 3). Whereas, sporulation is concern it is constant from control to $5 \mathrm{ppm}$ concentration. As we increased concentration of Fe sporulation is decreased. A $50 \%$ reduction in sporulation has been seen when we double the concentration from 5 to $10 \mathrm{ppm}$. It indicates that very little amount of Fe e.g. 5 ppm is required for radial growth and spore production of Pyricuariaoryzae. A higher concentration of Fe keeps a lethal effect on the fungus. Many other workers have demonstrated similar results in the case of Alternaria tenuis, Fusarium, Colletotrichum capsci and Pyricularia oryzae (Mishra and Mahmood, 1959; Saraswathi Devi 1958; Apparo et al. 1955) ${ }^{[11-13]}$.

(B) Effect of Manganese (Manganese Chloride) on growth and microsclerotia formation of Pyricularia oryzae

Table 4

\begin{tabular}{|c|c|c|c|c|}
\hline \multirow{2}{*}{$\begin{array}{c}\text { Concentration } \\
(\mathbf{p p m})\end{array}$} & \multicolumn{3}{|c|}{ Radial Growth (mm) $*$} & \multirow{2}{*}{$\begin{array}{c}\text { Microsclerotia Formation at } 96 \\
\text { hrs of Incubation }\end{array}$} \\
\cline { 2 - 4 } & $\mathbf{2 4}$ & $\mathbf{4 8}$ & $\mathbf{7 2}$ & \\
\cline { 2 - 4 } & 24.5 & 67.4 & 75.3 & ++ \\
\hline 0 & 20.4 & 64.3 & 74.0 & ++ \\
\hline 5 & 18.9 & 62.4 & 69.5 & ++ \\
\hline 10 & 25.8 & 70.0 & 78.4 & +++ \\
\hline 20 & 28.9 & 72.4 & 80.5 & +++ \\
\hline
\end{tabular}

*Average of 5 replication; one plate constitute one replication 
+ Less than 5 sclerotia/objective

++ 6-10 sclerotia/objective

+++ More than 10 sclerotia/objective

The predetermined quantity of $\mathrm{Mn}$ as per the calculations mentioned in materials and method was added in the medium. When the concentration of $\mathrm{Mn}$ is 2 and $5 \mathrm{ppm}$, the redial growth is less than the controlled concentration. The lowest radial growth $18.9 \mathrm{~mm}$ is reported at $5 \mathrm{ppm}$ (table 4). After this, the radial growth increased dramatically when the concentration was increased. Maximum growth was reported 28.9 in 24 hours, 72.4 in 48 hours, and 80.5 in 72 hours at 20 ppm. It seems that Pyricularia oryzae takes some time to get acclimatize to the Mn. After some time it gets adapted and probably produces some enzymes which help in the absorption of the Mn. Fall in the radial growth at $5 \mathrm{ppm}$ is a matter of further investigation. A similar observation also appears in sporulation. As we increased Mn concentration sporulation increased and after $10 \mathrm{ppm}$ it gets steady. Some report says that $\mathrm{Mn}$ is required in very small quantity in the medium i.g. 0.005 to $0.01 \mathrm{ppm}$ whereas, in our study we found that Pyricularia oryzae required more quantity for its better growth and sporulation. Donald et al. (1952) ${ }^{[14]}$ and Sulochana and Lakshmanan (1968) ${ }^{[15]}$ have observed that Mn deficiency reduced $50 \%$ growth of A. niger. Jinghua et al. (2004) ${ }^{[16]}$ observed that the application of Mn along with Trichoderma reduced the melon wilt caused by Fusarium sp.

(C) Effect of Molybdenum (Sodium Molybdenum) on growth and microsclerotia formation of Pyricularia oryzae

Table 5

\begin{tabular}{|c|c|c|c|c|}
\hline \multirow{2}{*}{$\begin{array}{c}\text { Concentration } \\
(\mathbf{p p m})\end{array}$} & \multicolumn{3}{|c|}{ Radial Growth (mm) * } & \multirow{2}{*}{$\begin{array}{c}\text { Microsclerotia formation at 96 } \\
\text { hrs of incubation }\end{array}$} \\
\cline { 2 - 4 } & $\mathbf{2 4}$ & $\mathbf{4 8}$ & $\mathbf{7 2}$ & \\
\cline { 2 - 4 } & 27.0 & 70.8 & 82.4 & ++ \\
\hline 0 & 26.4 & 69.4 & 80.2 & ++ \\
\hline 5 & 25.6 & 68.4 & 79.5 & ++ \\
\hline 10 & 24.3 & 62.5 & 76.8 & ++ \\
\hline 20 & 24.4 & 60.3 & 74.2 & + \\
\hline
\end{tabular}

*Average of 5 replication; one plate constitute one replication

+ Less than 5 sclerotia/objective

++ 6-10 sclerotia/objective

+++ More than 10 sclerotia/objective

Mo was added in the form of Sodium molybnate in the medium and radial growth and sclerotia formation were recorded. Maximum growth, as well as sporulation, is reported at controlled conditions i.e. 0 ppm (table 5). After that, as we increased the concentration of Mo radial growth is decreased respectively at all the incubation period. Sporulation is minimum at $20 \mathrm{ppm}$. It shows that a very minute quantity of the Mo is sufficient for the growth and spore development of the Pyriculariaoryzae. A small change in concentration of the Mo poses a negative effect on growth and sporulation. Adding a small amount of Mo in the medium will minimize the growth of Pyricularia oryzae. There are reports that A. Niger and Neurosporacrassa require more Mo otherwise, for most of the fungi its requirement is very minute (Steinberg, 1936) ${ }^{[17]}$. 


\section{CONCLUSIONS}

The primary goal of the agriculture scientist and plant pathologist is to minimize the spread of various diseases caused by fungi. One of the most common cause of declining Rice crop productivity is P. oryzae. By manipulating the concentration of these trace elements, we can control the growth of $P$. oryzae. An increase in concentration of $\mathrm{Fe}$ and Mo is beneficial to minimize the spread of the disease. Whereas, Removal of the Mn from the food chain reduces the growth and spread of the blast disease. This is an elementary work which provides a platform for further research.

\section{PHOTOGRAPH}

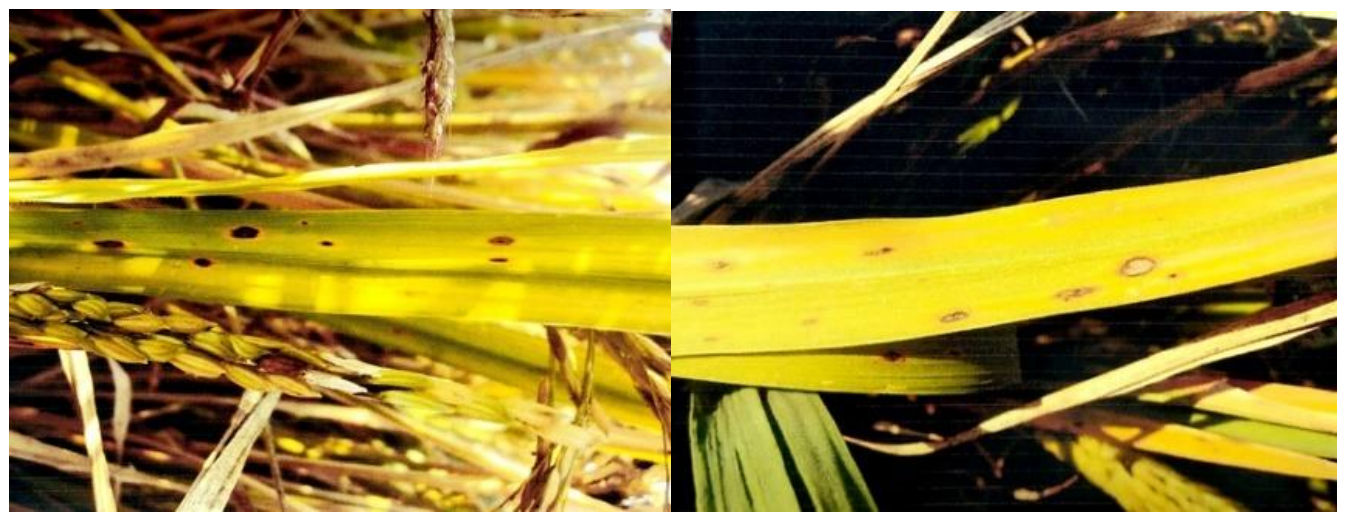

Photograph showing blast disease on leaves of the Rice plants.

\section{REFERENCES}

1. S.C. Scardaci et al.(1997). Rice Blast: A New Disease in California, Agronomy Fact Sheet Series, Department of Agronomy and Range Science University of California, Davis.

2. Godbold, D.L. et al. (1985). Effect of Zinc, Cadmium and Mercury on root elongation of Picea abies (Karst.) seedlings and the significance of the these metals to forest die-back. Environmental pollution. 38: 375-381

3. Reshma, M. R., et al. "Delineation and Mapping of soil available Iron and Copper status in Soils of Salem district of Tamil Nadu Using GIS and GPS Techniques." International Journal of Agricultural Science and Research 6.2 (2016): 295-300.

4. Breckle, S.W. (1991).Growth under Stress: Heavy Metal. In: Plant Roots: The Hidden Half, Marcel Dekker, New York, 351-373.

5. Nies, D.H. Microbial (1999) Heavy-Metal Resistance. Applied Microbiology and Biotechnology: 51, 730-750.

6. Sharma, R.(2020) Effect of Trace Elements $\mathrm{Zn}, \mathrm{B}, \mathrm{Mg}$ and $\mathrm{Cu}$ on the Growth and Sporulation of Pyricularia oryzae, the Causal Organism of Blast Disease of Rice. Current Botany, Vol. 11, pp. 121-124,

7. Foster, J.W et.al. (1993). The specific effect of Zinc and other heavy metal on growth and fumaric acid production by Rizopus. J. Bact.: Vol 37: 509-617

8. Reshma, M. R., et al. "Delineation and Mapping of soil available Iron and Copper status in Soils of Salem district of Tamil Nadu Using GIS and GPS Techniques." International Journal of Agricultural Science and Research 6.2 (2016): 295-300.

9. Allaway, W.H. (1965). Th trace elements in biological system. In: Trace analysis physical method(Ed. G. H. Morrison) Interscience Publisher, John Wiley \& Sons, New York. 
10. Lilly, V.G. (1965). The chemical environment for fungal growth. I. Media Macro and Micronutrient. In: The fungi. An Advanced Treatis, Vol I. The fungal cell 465-478.(Ed.). Ainsworth, G.C. Sussman, A.S. Acadeic Press, New York and London.

11. Bowen, H.J.M. (1966). Trace Elements in Biochemistry. Academic Press, London.

12. Mounika, M., K. U. Devi, and S. SUCHARITHA DEVI. "Bioavailability of iron from foxtail millet and sorghum millet recipes." Int. J. Agric. Sci. Res.(IJASR) 7.4 (2017): 703-708.

13. Thind, K.S. et.al. (1977). Effect of various trace elements on the growth and sporulation of four fungi. Proc. Nat. Sci. Acad. 43 part B, No. 4, 115-124

14. Mishra, A.P. et.al. (1959) .Effect of trace elements on growth and sporulation of $\quad$ C.capsici.Sci. and Cult. 25; 210-211

15. Saraswathi Devi (1958). Essentiality of trace-elements to some soil fungi. J.IndianBot.Soc. 37: 509-516

16. Kashyap, Rachit, and K. S. Verma. "Seasonal variation of certain heavy metals in Kuntbhyog lake of Himachal Pradesh, India." J Environ Ecol Fam Urb Stud 1.1 (2015): 15-26.

17. Apparao, A., L. (1955). Growth requirement of Pyricularia oryzae. J.Indian Bot. Soc. 34; $37-42$

18. Donald, C.B. (1952). Bioassay of trace metal deficiency on some Trichophyton strains. Aust J Agr. Res. 3: $305-$ 325

19. Sulochana, C.B. et.al. (1968). Aspergillus niger technique for the bioassay of manganese. J.Gen.Microbiol. 50: 285-293

20. Jinghua (2004). Effect of nutrition element on biocontrol efficiency of Trichoderma against melon wilt. ActaPhytophylacicaSinica. 31(4): 359-364

21. Steinberg, R.A. (1936). Some effect of heavy metals essentials for the nutrition of Aspergillus niger. Am. J. Bot. 23: $227-232$ 